development of an optical eddy-counting technique, including a focusing device; the measurement, by means of the hot-wire technique, of turbulence, velocity and temperature distribution along the jet; the examination of noise from jets of non-circular shape; and the study of noise emitted from special jet extensions, with annular corrugated orifices, designed to reduce low-frequency noise. Important fundamental research on the origin and nature of jet noise is also proceeding at the Universities of Manchester and Edinburgh.

The problem of aircraft noise was also debated in the House of Lords on July 7, when, for the most part, the question of legislation and responsibility for minimizing noise was discussed. Lord Hawke said that perhaps the most hopeful line of approach is in experiments with devices which act upon the gas when it leaves the jet and provide something in the nature of a gigantic exhaust box.

\section{PHYSICAL SOCIETY ANNUAL REPORT FOR 1953}

A

$T$ the annual general meeting of the Physical Society, held at the Royal Institution, London, on May 25, the reports of the council and of the honorary treasurer and the accounts and balance sheet for 1953 were presented and adopted. During the year the membership rose by 29 to 2,130 , and the sale of publications continued to increase both at home and abroad. The new scheme of subscriptions which came into operation on January 1, 1953, by which subscriptions for publications are separated from the subscriptions for membership, has worked smoothly and appears to be serving better the needs of members. There has also been a steadily growing interest in the reprint service which was introduced at the same time. The treasurer's report shows that any loss of income resulting from the lowering of the Fellows' subscription from three to two guineas has been more than compensated for by the increased income from the sale of publications of the Society. The cost of the provision of Science Abstracts, now no longer provided to members, was reduced from approximately $£ 2,500$ to $£ 500$. The income accruing to the Society as a result of the publication of the "Handbook of Scientific Instruments and Apparatus", the catalogue of the Society's 1953 exhibition of scientific instruments and apparatus, was considerable, amounting to nearly $£ 4,000$, and the balance of income over expenditure for the year was $£ 1,794$.

In addition to five science meetings held in London during the year, two-day meetings were held at the University of Leeds during March 31-April 1, and at King's College (University of Durham), Newcastle upon Tyne, during July 13-14; a conference on ionization phenomena in discharges, sponsored jointly by the Electrical Research Association, the Institute of Physics and the Physical Society, was held at the Clarendon Laboratory, Oxford, during July 18-23. The thirty-seventh Guthrie Lecture was delivered by Prof. Max Born, who spoke on the conceptual situation in physics and its prospects of development. The eighth Holweck Medal of the Société Française de Physique and the Holweck Prize of the Physical Society were presented to Mr. J. A. Ratcliffe in Paris in May, when Mr. Ratcliffe delivered the Holweck Discourse on the subject of diffraction of radio waves by the ionosphere. Prof. J. Bartels, of the University of Göttingen, received the seventh Charles Chree Medal and Prize on October 23, and for his address described Chree's influence on presentday geophysies. The thirtieth Duddell Medal was presented to Prof. W. Sucksmith, who gave a talk on "Some Magnetic Measurements-Techniques and Applications", and the ninth Charles Vernon Boys Prize to Prof. F. C. Williams, who spoke on "CathodeRay Tube Storage for Digital Computers".

Brief details of the activities of the four Groups of the Society, the Colour, Optical, Low Temperature and Acoustics Groups, together with a list of the numerous bodies on which the Society is represented, are given in the annual report. The activities of the Groups were not so varied as in former years, though the usual science meetings and summer meetings were held. The expenditure of the Groups fell markedly during the year, and, although the expense of the Groups to the Society was thus less than usual, it is emphasized that this is not a healthy sign since the activities of the Groups are vital to the welfare of the Society and any financial commitment entailed in their activities is more than offset by the contribution made by the Groups to the well-being of the Society.

At the annual general meeting the officers and council of the Society for 1954-55 were elected as follows : President, Prof. H. S. W. Massey ; Vice. Presidents in addition to ex-Presidents, Mr. J. H. Awbery, Dr. R. C. Evans, Dr. A. B. Wood and Prof. S. Devons ; Honorary Secretaries, Dr. C. G. Wynne, Dr. H. H. Hopkins ; Honorary Foreign Secretary, Prof. E. N. da C. Andrade ; Honorary Treasurer, Mr. A. J. Philpot; Honorary Librarian, Dr. R. W. B. Pearse; New Ordinary Members of Council, Dr. T. E. Allibone, Dr. A. H. Cooke, Prof. F. C. Frank and Prof. G. O. Jones.

\section{ARTIFICIAL AND NATURAL COLORATION OF DIAMONDS}

MOST diamonds in their natural state are 1 coloured; but the origin of the colour is still largely a mystery. There is little evidence that it is due to impurities, nor is it clear as to whether the colour is generally confined to the surface or distributed throughout the diamond, though in some cases, usually diamonds coloured yellow or yellowgreen, the colour has been reduced or removed by polishing and grinding the surface. The colour has then been attributed to natural radioactivity. In 1923, S. C. Lind and D. C. Barwell established that diamonds were coloured green by bombardment with alpha-particles from radium, and there have been several reports during the past decade of the colouring of diamonds by proton and deuteron bombardment, though beta-, gamma- and X-rays seem to have little or no effect. The evidence suggests that diamonds are more readily coloured by energetic heavy particles. This supports the theory that the colour centres are connected with the vacant lattice sites and interstitial atoms formed when the bombarding particles collide with the carbon atoms of the diamond lattice.

A recent study by R. A. Dugdale of the effect of neutron bombardment of diamonds in the Harwell pile BEPO and of high-energy electron bombardment and of subsequent heat treatment confirms this view 